\title{
Detection of Visual Signatures of Marine Mammals and Fish within Marine Renewable Energy Farms using Multibeam Imaging Sonar
}

\author{
Francisco Francisco *(D) and Jan Sundberg \\ Division of Electricity, Uppsala University, Box 534, 75121 Uppsala, Sweden; Jan.Sundberg@angstrom.uu.se \\ * Correspondence: Francisco.Francisco@angstrom.uu.se
}

Received: 11 November 2018; Accepted: 18 January 2019; Published: 22 January 2019

\begin{abstract}
Techniques for marine monitoring have been greatly evolved over the past decades, making the acquisition of environmental data safer, more reliable and more efficient. On the other hand, the marine renewable energy sector has introduced dissimilar ways of exploring the oceans. Marine energy is mostly harvested in murky and high energetic places where conventional data acquisition techniques are impractical. This new frontier on marine operations brings the need for finding new techniques for environmental data acquisition, processing and analysis. Modern sonar systems, operating at high frequencies, can acquire detailed images of the underwater environment. Variables such as occurrence, size, class and behavior of a variety of aquatic species of fish, birds, and mammals that coexist within marine energy sites can be monitored using imaging sonar systems. Although sonar images can provide high levels of detail, in most of the cases they are still difficult to decipher. In order to facilitate the classification of targets using sonar images, this study introduces a framework of extracting visual features of marine animals that would serve as unique signatures. The acoustic visibility measure (AVM) is here introduced as technique of identification and classification of targets by comparing the observed size with a standard value. This information can be used to instruct algorithms and protocols in order to automate the identification and classification of underwater targets using imaging sonar systems. Using image processing algorithms embedded in Proviwer4 and FIJI software, this study found that acoustic images can be effectively used to classify cod, harbour and grey seals, and orcas through their size, shape and swimming behavior. The sonar images showed that cod occurred as bright, $0.9 \mathrm{~m}$ long, ellipsoidal targets shoaling in groups. Harbour seals occurred as bright torpedo-like fast moving targets, whereas grey seals occurred as bulky-ellipsoidal targets with serpentine movements. Orca or larger marine mammals occurred with relatively low visibility on the acoustic images compared to their body size, which measured between $4 \mathrm{~m}$ and $7 \mathrm{~m}$. This framework provide a new window of performing qualitative and quantitative observations of underwater targets, and with further improvements, this method can be useful for environmental studies within marine renewable energy farms and for other purposes.
\end{abstract}

Keywords: multibeam imaging sonar; visual signature; marine mammal; seal; fish; marine renewable energy

\section{Introduction}

Given the high potential that clean harvesting technologies have, marine renewables soon may be integrated into the energy mix. Yet, there are concerns arising from the potential hazard that wave, tidal and offshore wind energy converters may cause to marine organisms and to the environment [1-3]. In general, the exploration of renewable energy in the marine environment takes place where the physical conditions are dominated by high seas, strong winds, deep and 
murky waters $[4,5]$. In this early phase of implementation of commercial marine renewable energy farms, there is a need to investigate the characteristics of man-made effects resulting from the energy conversion on the marine environment. Due to the high energy content at marine renewable energy sites, conventional monitoring techniques may not work in the prevailing harsh conditions that may result in unsafe, unreliable and costly data acquisition. For example, scientifically approved methods of observing marine mammals and fish still involve the direct human observation, the use of cameras, tags, echo-sounders, capture and diving [6,7]. These conventional techniques require substantial resources while incurring high risks and costs. However, these limitations can be addressed by utilizing alternative technologies such as high frequency sonar systems [8,9].

Modern sonar system are capable of operating in harsh conditions while acquiring photo-like acoustic images. Sonar systems can be attuned and integrated into multifunctional platforms that safely and lengthy collect data of parameters such as the occurrence, behavior, size and class of a variety of aquatic species coexisting within marine energy sites. Sonar systems have recently become a preferential tool utilized for the monitoring of the marine environment at several renewable energy sites worldwide. For example, references [2,5-14] utilized sonar systems to monitor the interaction between fish, marine mammals, tidal turbines and wave energy converters (WECs). The Uppsala University (UU) in Sweden, through the Lysekil wave power project, have been researching and developing marine renewable energy technologies as well as environmental monitoring techniques. An example of previous environmental studies was presented by references [15-17] and has found indications of occurrence of artificial reefs introduced by WECs as well as radiated noise from the machinery. In the case of artificial reefs, most species colonizing these reefs were small-size fish and invertebrate including crustacean, which likely benefited from the protection, food and shelter that these hard reefs provide. However, little is known about the effects on larger species, such as marine mammals (ex: seals, dolphins), large fish (e.g. cod) or large aggregations (ex: schools of herring, sprat or mackerel). Due to risks such as collision $[18,19]$, it is also imperative to understand the behavior of lager marine animals within marine renewable energy sites. For example, it would be ideal to have quick response monitoring systems that are able to trigger alarms in the event of large marine animals entering into energy farms. Such alarm systems would be important in sites with tidal turbines. Similar to optical cameras, LIDAR, RADARs and human-observations, the multibeam sonar systems (MBS) can be used to monitor the occurrence and behavior of animals, especially in murky and dark waters, and provide photo-like acoustic images of subsea targets located in the water column. The instrumentation necessary to perform such monitoring tasks already exists. However, the data acquisition and processing framework is not yet ready, which makes it difficult and time-consuming to automate the process of identification and classification of underwater marine animals.

In an MBS, acoustic energy is emitted and received in multiple angles across-track swath, typically in a fan shape [20,21]. Transmitting and receiving elements are arranged in 2-dimensiconal arrays. Generally, each element transmits pulses (signals) individually in a crescent order, and the echoes are received simultaneously by all receivers. However, each echo is processed separately, enabling a number of echo-beams to be formed by combining the outputs of the several arrays of transducing elements with different phasing functions. This setup effectively steers the beam in several directions simultaneously. Furthermore, these elements are arranged in a spiral configuration so that the beam pattern fills the field of view (FOV). The number of beams can reach up to 1500 unities in angular sectors up to $180^{\circ}$ of FOV. Modern MBS systems can operate from frequencies of $200 \mathrm{kHz}$ up to $3 \mathrm{MHz}$, obtaining range resolutions of up to $1 \mathrm{~cm}$ and an angular resolution of approximately $0.2^{\circ}$. The use of several narrow beams, with a minimized transmit-pulse (beam spacing), maximizes the effective sampling volume covered in the entire swath in a single ping. One of the main limitations of multibeam imaging sonar systems is the short range, which is limited to less than $\pm 100 \mathrm{~m}$, which is due to high operating frequencies. High sensitivity to background noise is other prominent limitation of such sonar systems. Noise generated by the seabed and surface turbulence may also affect the signal, mainly when the target is located at a greater distance than the bottom depth [22,23]. Bubbles 
within the swath cause intense noise, mainly in sonar systems operating with very high frequencies. Multibeam sonar systems generate large volumes of data, and the processing and analysis of the data may be complex and time consuming.

The objective of the present study is to propose an easy target detection and classification framework that can facilitate the interpretation of acoustic images of fish and marine mammals. The main idea is to extract the characteristic shape and size of underwater targets observed through acoustic images and extrapolate the respective visual signatures. These signatures can be used to train the human eye as well as computer algorithms to automatically identify and classify targets of interest. In this light, the present study uses the data acquired by a MBS deployed with a multifunctional monitoring platform at the Lysekil wave power test site. The data set consisting of 311740 images was processed and analyzed in order to obtain the shape, size, and swimming behavior of fish, seals and larger marine mammals.

The ultimate goal of this study is to propose a safe, reliable and straightforward technique of processing information that can be used for a better planning, monitoring and implementation of marine renewable energy projects.

\section{Methods}

\subsection{Survey Design}

An MBS system was used to acquire data in the period between 23rd August and 1st September 2016 at the Lysekil wave power test site which is located on the Swedish west coast $\left(58.274219^{\circ} \mathrm{N}\right.$, $11.450808^{\circ} \mathrm{E}$, [24]). The MBS system (Table 1) was deployed at $25 \mathrm{~m}$ of depth with the transducer orientated upwards, $0.7 \mathrm{~m}$ above the seabed, with a pitch angle of $\alpha_{M B S}=10^{\circ}$ relative to normal (Figure 1). Two UU-WECs were covered within the sonar FOV, WEC A was located at $30 \mathrm{~m}$ of range with a yaw angle $\left(\theta_{M B S}\right)$ of $58^{\circ}$, and WEC B was located at $50 \mathrm{~m}$ of range with a yaw angle of $52^{\circ}$. Part of seabed and sea surface were also covered in such a way that the FOV intercepted the sea surface plane at $25 \mathrm{~m}$ of range shown as point " $\mathrm{i}$ ", as well as the seabed plane at point "ii" (Figure 1a) The area ahead of point " $\mathrm{i}$ " contains data of backscatter intensity from the water column and sea surface. The area before point "ii" mainly contains data of targets within the water column and seabed (Figure 1a).

Table 1. Technical specifications of the multibeam imaging sonar used in this study.

\begin{tabular}{cc}
\hline Component & Specification \\
\hline & Frequency: $0.9 \mathrm{MHz}$ (operational) \\
Number of Beams: 768 \\
MBS BlueView M900-130-S-MKS-VSDL & Refresh rate: up to $50 \mathrm{~Hz}$ (sample frequency) \\
& FOV: $132^{\circ} \times 20^{\circ}$ (field of view) \\
& Resolution: $0.18^{\circ} / 2.54 \mathrm{~cm}$ \\
Maximum range: $100 \mathrm{~m}$
\end{tabular}



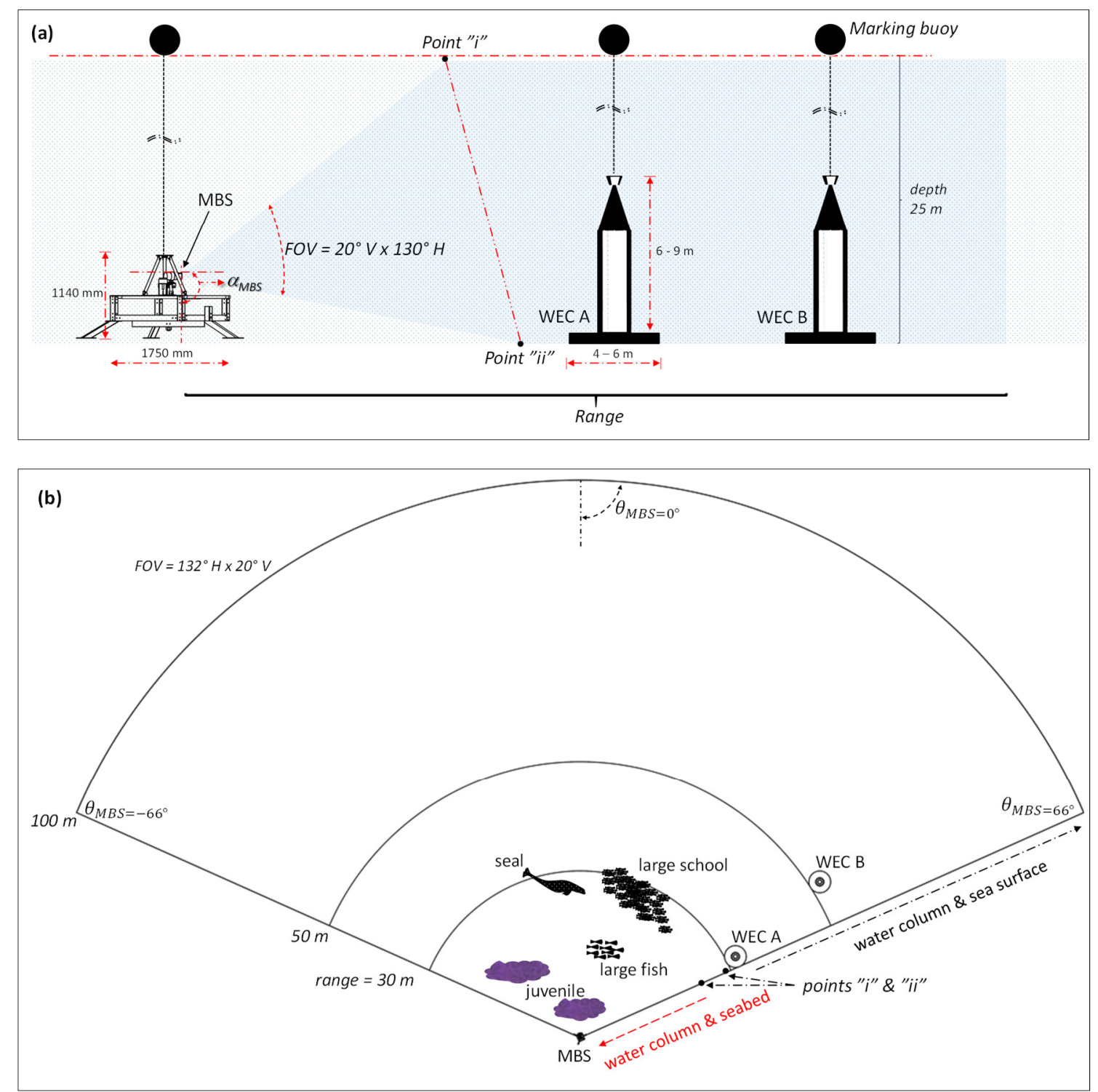

Figure 1. (a) Lateral and (b) top view-scheme of the acoustic images acquired by the multibeam sonar (MBS) at distances of $30 \mathrm{~m}$ and $50 \mathrm{~m}$ from WECs A and B, respectively. The field of view (FOV) had a width of $82 \mathrm{~m}$ or $130^{\circ}\left(\theta_{M B S}=-66^{\circ}\right.$ to $\left.+66^{\circ}\right)$, height of $20^{\circ}$ and maximum range of $100 \mathrm{~m}$, the MBS pitch angle $\left(\alpha_{M B S}\right)$ was set to $10^{\circ}$.

\subsection{Data processing Protocol}

Data were acquired in burst, each lasting $960 \mathrm{~s}$ (16 min), separated by $2820 \mathrm{~s}$ (47 $\mathrm{min}$ ) of stand by time in order to save power and memory. Each burst resolved 1199 samples at $1.25 \mathrm{~Hz}$, making a total of 311740 samples contained in 260 sets of data. The data was processed through 6 levels, starting from raw data (levels 0-2), attributed data (level 3, ex: acoustic images), interpolated data (levels 4-5, ex: filtered acoustic images), and extrapolated data (level 6, ex: target features derived from filtered images at levels 3-5). Essentially, the raw data forming an acoustic image was made of sequences of pings (emission + echoes $=$ insonification). Each ping comprised an aggregate of 768 beams separated by $0.18^{\circ}$ and contained information of backscatter intensity, range, angle, velocity and georeferenced data. The precision was estimated to be $\pm 0.1 \mathrm{~m}$ of the measured distance between two points within the acoustic image reproduced in ProViwer4. Table 2 and Figure 2 show the calibration parameters and data acquisition and processing scheme. 
Raw data at level 0 was acquired as electrical signals, then pre-processed and compensated with time varied gain (TVG), using BlueView SDK 3.6 [25], turning the data into level 1. The data was further processed and visualized in ProViwer4 software at two levels: level 2 containing all background noise, and level 3 resulting in most of the noise being removed. To obtain the acoustic signatures from targets of interest, the data (acoustic images) went through processing levels 4 and 5 using supervised algorithms in FIJI-ImageJ2 (and Matlab2018a) software. Before activating filters in FIJI, appropriate thresholds needed to be applied to the images [26]. In the present work, the images were adjusted to 32-bits before applying the Otsu or $L i$ thresholds [26,27] in black and white (level 4). In the level 5, image filters such as binary, outline, edges and connected regions were applied. Moreover, in levels 4 and 5, valid targets were assigned as valid image pixels, then selected as representation of a specific category (also designated as training). The analysis processing algorithm used this information (training) as a reference to be used to classify all other images. This process was repeated and improved several times in order to strengthen this target classification system that culminated with the extraction of target signatures (level 6). The level 6 represents the extrapolated data that clearly showed the unique and simplified shape of targets. Features such as shape and size were re-constructed using computer aided design software Solidworks 2013 and using the interpolated data of acoustic images at levels 3-5. The Solidworks 2013 software was also utilized for building the three dimensional models of each assumed target that facilitated the visualization and identification of targets.

Table 2. The calibration parameters used for processing the images.

\begin{tabular}{|c|c|c|}
\hline ProViwer4 & $\begin{array}{c}\text { Sound speed: } 1500 \mathrm{~m} / \mathrm{s} \mid 1527 \mathrm{~m} / \mathrm{s} \\
\text { Sensitivity: } 19.9 \mathrm{~dB} \mid 29.4 \mathrm{~dB} \\
\text { Intensity: } 90 \mathrm{~dB} \mid 95.9 \mathrm{~dB} \\
\text { Gama: } 0.5 \mid 1.2\end{array}$ & Levels 2 | 3 images \\
\hline FIJI-ImageJ2 & $\begin{array}{c}\text { Threshold and filters: } \\
\text { - } 8 \text { | } 32 \text { bit binary } \\
\text { - Outline | Edges | Skeletonize } \\
\text { - Connected regions }\end{array}$ & $\begin{array}{l}\text { Level } 4 \text { images } \\
\text { Level } 5 \text { images } \\
\text { Level } 5 \text { images }\end{array}$ \\
\hline Solidworks2013 & $\begin{array}{l}\text { - Building of 3-D models } \\
\text { - Reconstruction of shape and size }\end{array}$ & Level 6 images \\
\hline
\end{tabular}

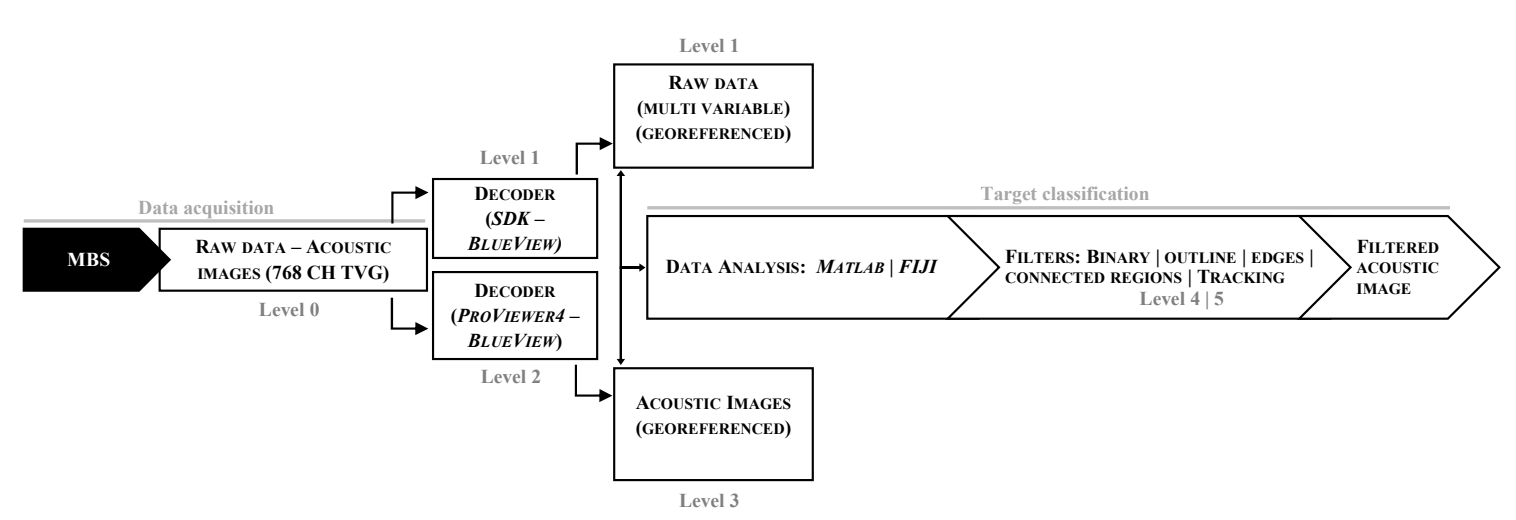

Figure 2. Schematic view of the routine used for data acquisition and processing. The multibeam sonar (MBS) raw data was firstly processed by the SDK/ProViwer4 software. The acoustic images were visualized using SDK/ProViwer4 and filtered using FIJI-ImageJ2 or Matlab2018a - Image processing Toolbox.

\subsection{The Acoustic Visibility Measure}

This study introduces a new approach of accessing the visibility of fish and marine mammals using acoustic images that can improve the identification and classification of targets using sonar systems. The acoustic visibility measure (AVM) is the ratio between the expected and observed length or diameter of a target. The AVM can now be estimated as follows: the target position $(T)$ within the water column at an instant of time $t_{i}$ is a function of yaw $\left(\theta_{T}\right)$, pitch $\left(\beta_{T}\right)$, roll $\left(\gamma_{T}\right)$ and altitude 
$(z)$, i.e., $T\left(\theta_{T}, \beta_{T}, \gamma_{T}, z_{T}\right)$. The current MBS system made use of acoustic intensity and amplitude of the signal without the altitude $\left(z_{T}\right)$ of a target. Thus, the acoustic image $(I)$ acquired at given instant of time $t_{i}$ with a known signal to noise ration (SNR), will only contain the measured acoustic backscattering intensity as a function of beam angle $\left(\theta_{M B S}\right)$ and range $(r)$, i.e $I\left(\theta_{M B S}, r\right)$. Assuming that $I\left(\theta_{M B S}, r\right)$ is real and $T\left(\theta_{T}, \beta_{T}, \gamma_{T}, z_{T}\right)$ is the imaginary part of a complex quantity $R$, then the acoustic visibility measure will be a function of time and the position of the target within the water column in relation to the sonar FOV i.e., $A V M(R, t)$. Assuming that the $\gamma_{T}$ is negligible for qualitative analysis of target position, $R=I\left(\theta_{M B S}, r\right)+i T\left(\theta_{T}, \beta_{T}, z_{T}\right)$, then AVM can be estimated using Equation 2, below. The consequence of this arrangement is that the position and shape of a target can only be estimated indirectly.

$$
A V M=S N R \iint \frac{R_{o}}{R_{e}} d R d t
$$

where, $R_{e}$ is the expected radius or size, and $R_{o}$ is the observed or sonar-resolved radius or size of an insonified target. $R_{o}$ was obtained by measuring the target size with the inbuilt ruler of the ProViwer4 software, at $95 \%$ confidence interval. At time $t_{i}$ the Equation can take the simplified form:

$$
A V M=\frac{R_{0}}{R_{e}}
$$

The expected target size $\left(R_{e}\right)$. was obtained from the literature in references [28-31], as shown in Table 3.

Table 3. Expected target size of marine animals, values retrieved from the literature [28-31].

\begin{tabular}{cc|cc}
\hline Animal $\left(\mathbf{S}_{\mathbf{p p}}\right)$ & Size & Animal $\left.\mathbf{( S}_{\mathbf{p p}}\right)$ & Size \\
\hline $\begin{array}{c}\text { Atlantic cod } \\
(\text { Gadus morhua })\end{array}$ & $60 \mathrm{~cm}-1.2 \mathrm{~m}$ & $\begin{array}{c}\text { Grey seal } \\
\text { (Halichoerus grypus) }\end{array}$ & $\begin{array}{c}\text { Males 2-3.3 m, avg. 2m; } \\
\text { Females 1.6-2 m, avg. 1.8 m }\end{array}$ \\
\hline $\begin{array}{c}\text { Atlantic herring } \\
\text { (Clupea harengus) }\end{array}$ & $24-45 \mathrm{~cm}$ & $\begin{array}{c}\text { Harbour seal } \\
\text { (Phoca vitulina) }\end{array}$ & $\begin{array}{c}\text { Males avg. 1.7 m; } \\
\text { Female avg. 1 m }\end{array}$ \\
\hline $\begin{array}{c}\text { European sprat } \\
\text { (Sprattus sprattus) }\end{array}$ & $8-16 \mathrm{~cm}$ & $\begin{array}{c}\text { Orca } \\
\text { (Orcinus orca) }\end{array}$ & $\begin{array}{c}\text { Males 6-8 m; } \\
\text { Females 5-7 m; } \\
\text { Dorsal fin 0.9-1.8 m }\end{array}$ \\
\hline $\begin{array}{c}\text { Northeast Atlantic mackerel } \\
\text { (Scomber scombrus) }\end{array}$ & $30-66 \mathrm{~cm}$ & & \\
\hline
\end{tabular}

\section{Results and Discussion}

A total of 260 observations of six classes of targets were studied, based on 311740 acoustic images, and their acoustic signature analyzed. Basing on size and shape, targets measuring $1 \mathrm{~m}-2$ $\mathrm{m}$ of length were condered harbour seals (Phoca vitulina). The harbour seal is the most abundant species of seal in the Skagerrak area where the present study was conducted, and there is a seal colony close to this site [32]. Targets with 2-3 m of length were considered grey seals (Halichoerus grypus). The 4-7 m long targets were considered to be small whales and likely orcas (Orcinus orca). Fish were distinguished in classes, large $(40-90 \mathrm{~cm})$, medium $(20-40 \mathrm{~cm})$ and small fish $(<20 \mathrm{~cm})$. Large fish were considered to be cod (Gadus morhua), which also are an abundant species in the study area [28,29]. The small and mid-size fish could be either sprat, herring or mackerel. All of these three species normally measure between $8 \mathrm{~cm}$ and $45 \mathrm{~cm}$ and normally occur in schools [28,29,33]. Medium and small fish were always observed in schools, therefore instead of individuals, this study considered the characteristics of an entire school of fish. Information related to the species that occur in Swedish waters can be accessed in data bases such as the Global Biodiversity Information Facility (GBIF-Sweden) and the Baltic Marine Environment Protection Commission-Helsinki Commission (HELCOM) [34,35]. Table 4 shows the classification of these targets in terms of class, size and approximate geometric shape. 
Table 4. Size of observed targets $\left(R_{0}\right)$ obtained using acoustic images.

\begin{tabular}{ccccccc}
\hline Class & Harbour Seal & Grey Seal & Orca & Small Fish & Medium Fish & Cod \\
\hline Observed length & $1-2 \mathrm{~m}$ & $2-4 \mathrm{~m}$ & $>4 \mathrm{~m}$ & $<20 \mathrm{~cm}$ & $<40 \mathrm{~cm}$ & $>40 \mathrm{~cm}$ \\
\hline $\begin{array}{c}\text { Approximated } \\
\text { geometric shape }\end{array}$ & ellipsoidal & ellipsoidal-bulkier & $\begin{array}{c}\text { ellipsoidal } \\
\text { streamlined-bulkier }\end{array}$ & ellipsoidal & ellipsoidal & ellipsoidal-bulkier \\
\hline $\begin{array}{c}\text { Observed } \\
\text { swimming behavior }\end{array}$ & slow-fast & slow-fast & fast & slow-fast & fast & static-slow \\
\hline
\end{tabular}

Each class of targets has its characteristic AVM. Among the entire data set, samples of six to ten measurements were conducted in order to access the AVM of supposed harbour seals, grey seals, orcas and cod. For marine mammals i.e., seals and orcas, the AVM were estimated taking in consideration both male and female individuals. Estimations of AVM of small and mid-size fish were discarded in order to avoid large errors. Since AVM is a ratio between the observed and expected lengths, the values of AVM that were closer to one were equivalents to complete concordance of the target length. The AVM of the supposed harbour seals fell in the interval between 0.4 and 1.6 (Figure 3a), considering expected lengths $\left(R_{e}\right)$ of $1.7 \mathrm{~m}$ for males and $1 \mathrm{~m}$ for females. These measurements were conducted in targets with $R_{o}$ of $0.9 \mathrm{~m}$ to $1.6 \mathrm{~m}$ located within $6.6 \mathrm{~m}$ to $12.3 \mathrm{~m}$ of range. When grouped by sexes, the results show better concordance for the size of females compared to males. The estimated values of AVM of the supposed grey seals were between 0.6 and 1.5 (Figure 3b). The results show that the measured length of grey seals was similar to the expected length of female grey seals. Supposed grey seals were detected at ranges between $9.2 \mathrm{~m}$ and $15.8 \mathrm{~m}$. The AVM estimated from a sample of four supposed orcas had values of 0.6 to 1.1 (Figure 3c), and the measured target range varied between $5.2 \mathrm{~m}$ and $16 \mathrm{~m}$. The expected lengths was set to $6 \mathrm{~m}$ for females and $7 \mathrm{~m}$ for male orcas (Table 2). The estimated AVM showed slightly better concordance for females than males, although the differences were marginal. Most of the measurements of length of supposed cod were close to the expected value set as $0.9 \mathrm{~m}$. The supposed cod measured $0.4-0.8 \mathrm{~m}$ of length, resulting in AVM values of 0.4 to 0.9 (Figure 3d). The range of observed cod was between $4 \mathrm{~m}$ and $16 \pm 0.2 \mathrm{~m}$.
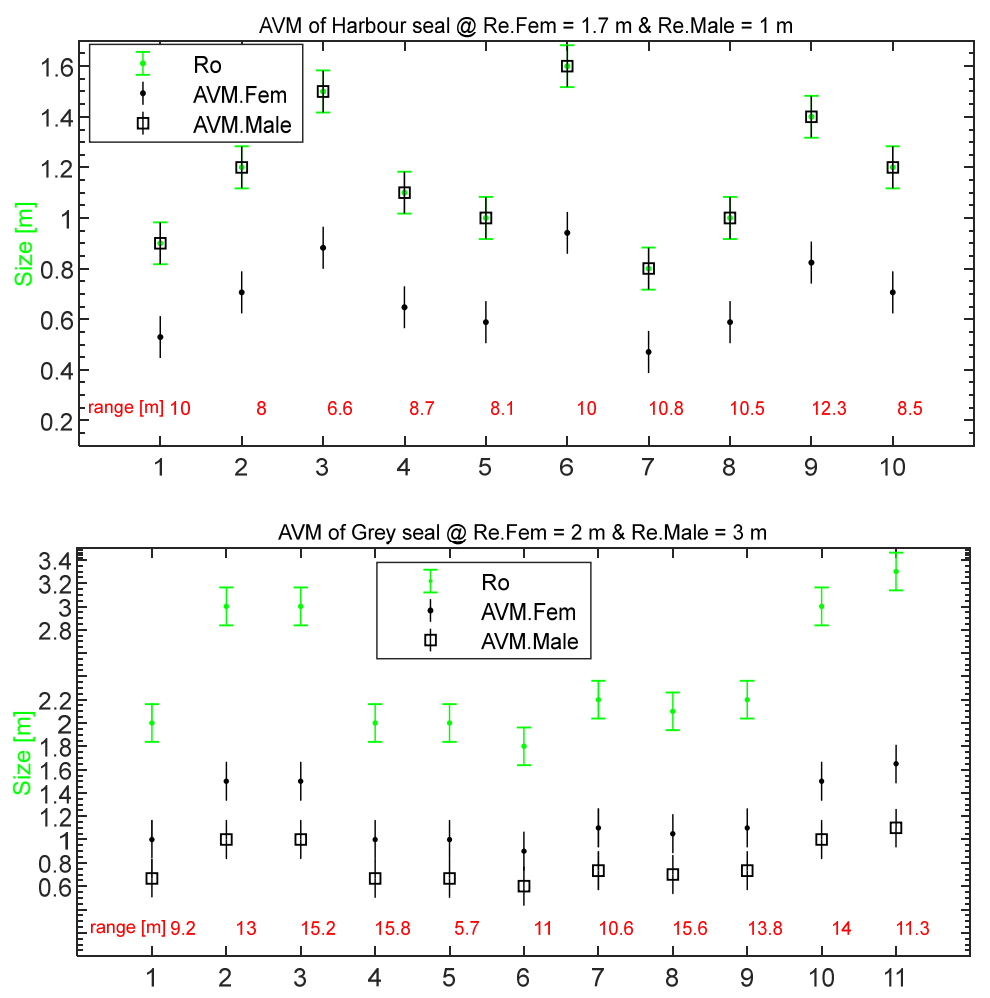

Figure 3. Cont. 

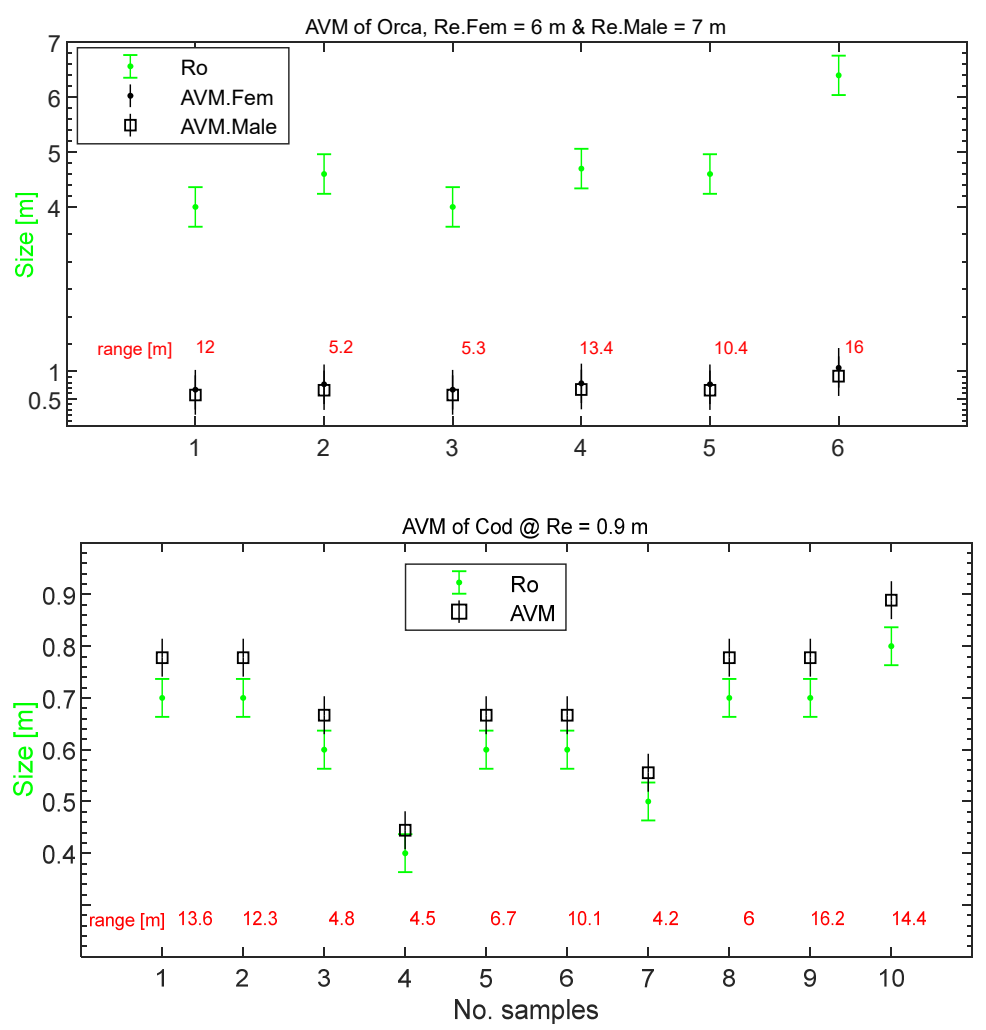

Figure 3. The Acoustic Visibility Measure (AVM) of (a) harbour, (b) grey seals, (c) orca and (d) cod. Re.Fem and Re.Male are the expected size for female and male animals respectively, and Ro is the observed size. The expected size $(R e)$ values were retrieved from the literature [28-31]. The range in which these targets were detected is given in red. The standard error is represented by the error bars with caps. The y-axis represent both the nondimensional AVM and the unidimensional size of targets.

\subsection{Schools of Fish}

The density of the school of fish makes it a good acoustic reflector and easy to detect by the sonar even at long range. Smaller fish, with lengths of up to $0.4 \mathrm{~m}$, were mainly observed moving in schools with diameters measuring $5 \mathrm{~m}$ to $20 \mathrm{~m}$ (Figure 4) and moving in a very dynamic manner and forming various figures. On several occasions seals and larger fish were observed chasing schools of small and mid-size fish. 


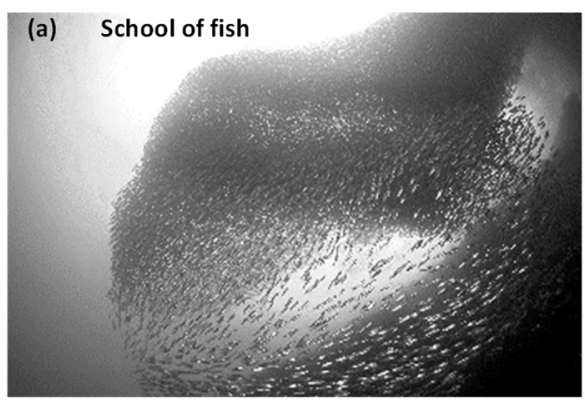

(c) Obs. school of mid-size fish (L-3)

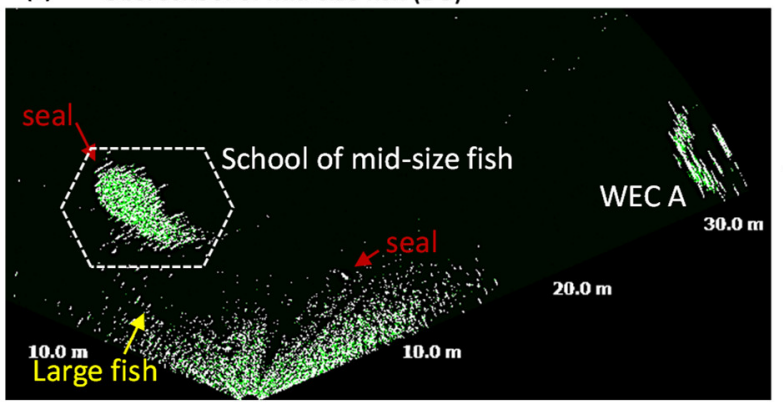

(f) Obs. school of small-size fish (L-3)

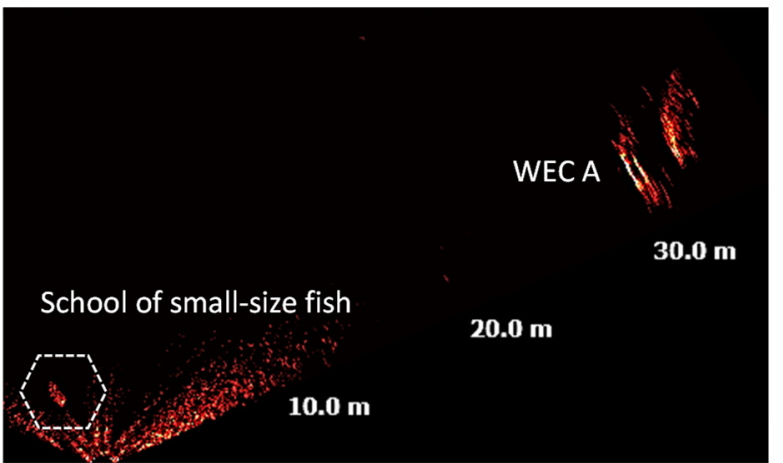

(b) 3D model: small and mid size fish

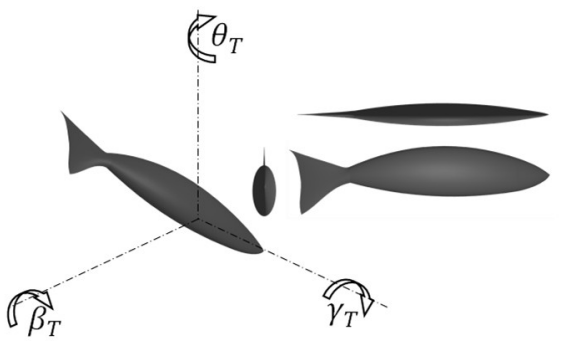

(d) Otsu threshold (L-4)

(e) Edge filter (L-5)

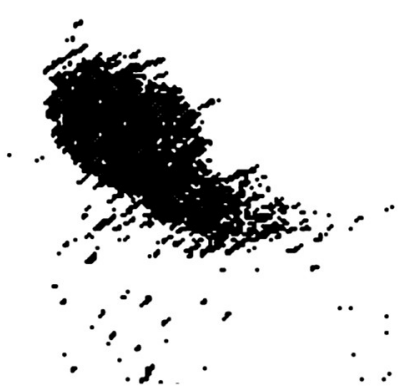

(g) Otsu threshold (L-4)

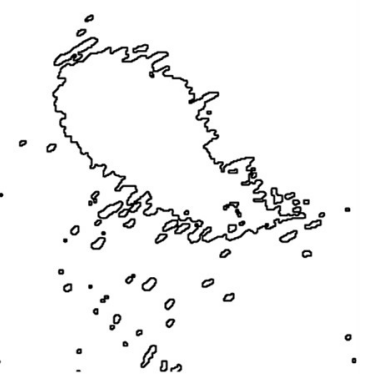

(h) Edge filter (L-5)

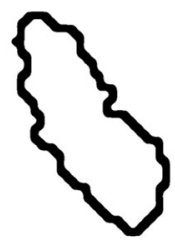

Figure 4. Visual signatures of schools of fish. (a) Assumed image of school of fish. (b) Computer rendering of a three dimensional (3D) model of small and mid-size fish, including the yaw $\left(\theta_{T}\right)$, pitch $\left(\beta_{T}\right)$, roll $\left(\gamma_{T}\right)$ angles. (c and f) Acoustic images processed on ProViewer4 at level 3 (L-3) showing a school of mid-size fish with (c) school with $12 \mathrm{~m}$ of diameter at 10-17 $\mathrm{m}$ of range; and (f) small-size fish, school with $1.5 \mathrm{~m}$ of diameter at 3.5-6 m of range. Shapes and silhouettes of schools of fish processed on FIJI with (d and $\mathbf{g}$ ) Otsu threshold; (e) Edge filter; (h) outline filter.

\subsection{Large Fish}

Most of the observed large fish were likely to be the Atlantic cod (Gadus morhua). The average measured length was $0.6 \mathrm{~m}$. These targets were seen through the MBS displaying ellipsoidal shapes (Figure 5). Targets such as cod mainly occurred during night time and were moving slowly within the FOV. At the peak of occurrence and perhaps activity, there were ca. 50 or more fish showing in the acoustic images as sparkling spots turning on-off on the FOV. Nevertheless, the MBS easily and clearly detected the supposed cod. 
(a) Atlantic Cod

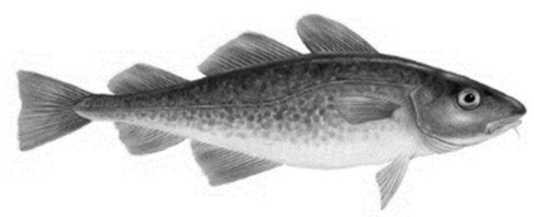

(c) Obs. $\operatorname{cod}(\mathrm{L}-3)$

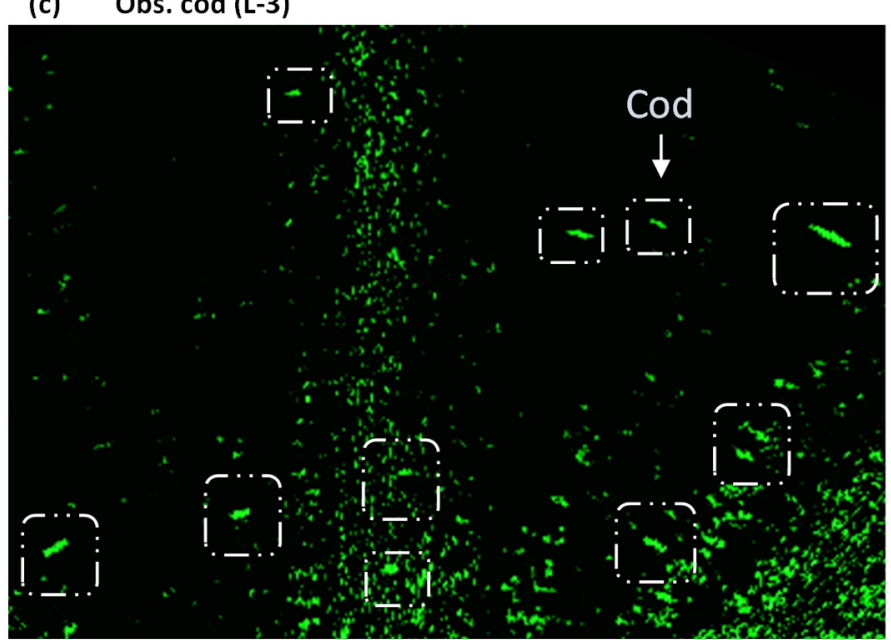

(b) 3D model: large fish

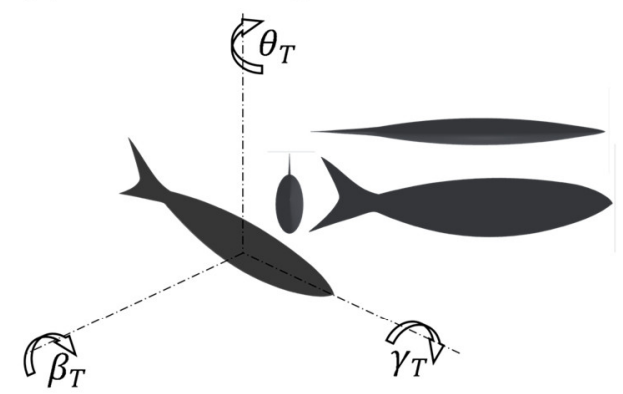

(d) Binary threshold (L-4)

Figure 5. (a) Image of cod [36]. (b) Three dimensional (3D) model of a cod. (c) Acoustic images at level 3 of a cod with $0.7-0.8 \mathrm{~m}$ of length, at 10-15 m of range; (d and e) Extracted shape and silhouette of a cod from the acoustic image in (c) using FIJI with: (d) binary threshold and (e) edge filter.

\subsection{Seals}

Based on size and shape, it can be expected that the observed seals belong to two species, the harbour or common seal (Phoca vitulina) and the grey seal (Halichoerus grypus). In terms of size, the assumed harbour seals measured 0.9-1.4 $\mathrm{m}$ and were detected swimming alone or in groups up to six individuals. The assumed grey seals measured ca. $2-3.5 \mathrm{~m}$ and occurred as single or as a group of two individuals. In terms of target insonification, the harbour seals reflected sound much more effectively and were easier to detect than the bulkier grey seals. Both harbour and grey seals swam in a snake-like manner forming "S", "I" and " $\mathrm{U}$ " shapes through the water $[31,37]$. The wobbling swimming pattern may be more pronounced in grey seals as they are longer in size and are therefore more flexible than the smaller harbour seals. The harbour seals appeared mostly in the acoustic images as bright torpedo like targets forming ellipsoidal shapes (Figure 6). At certain angles and range, the acoustic signature of harbour seals could be similar to a large fish such as cod, except that the size was both longer and wider. On the other hand, the acoustic signature of the grey seals varied from a torpedo like shape in the form of a bulky and elongated ellipsoid (Figure 7), to a rather complex multi spot target displayed as set of one to four bright and narrow ellipsoidal spots. The signatures of grey seals at certain angles and ranges could be mistaken as groups of large fish or even harbour seals. 
(a) Harbour seal

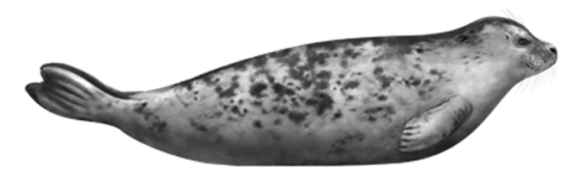

(c) Obs. harbour seal (L-3)

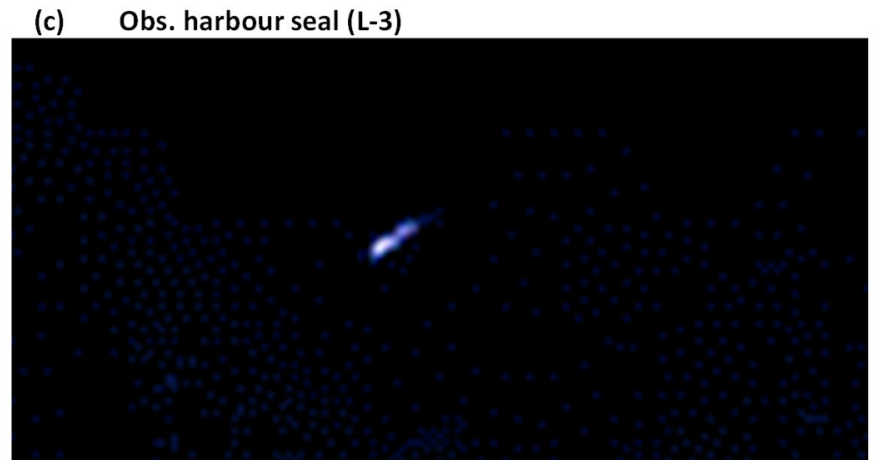

(f) Obs. harbour seal (L-3)

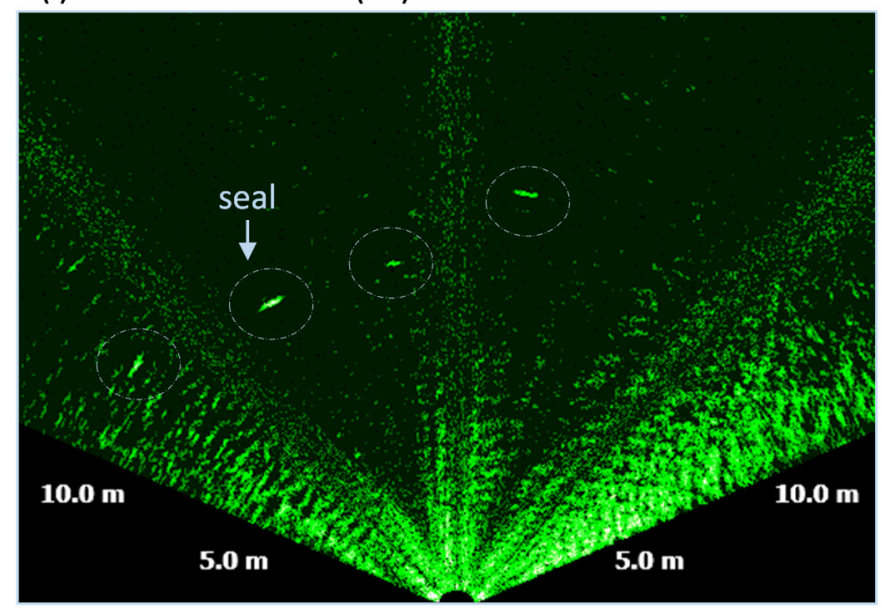

(b) 3D model: harbour seal

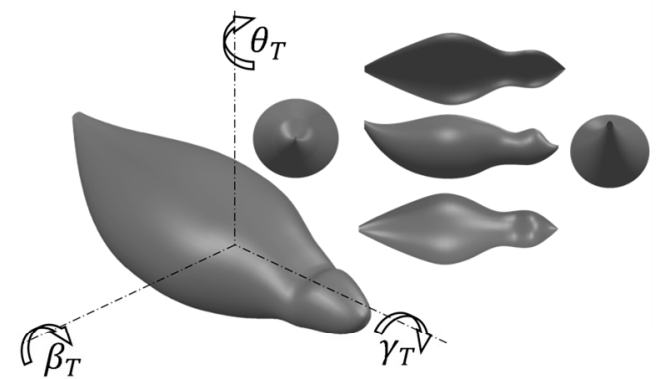

(d) Li threshold (L-4)

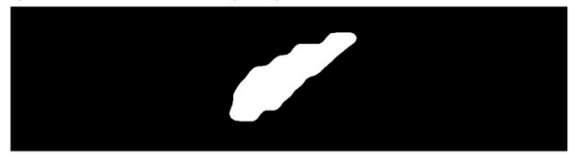

(e) Edge filter (level-5 image)

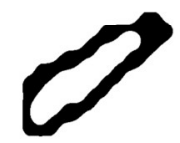

(g) Li threshold (L-4)

$i$

(h) Outline filter (L-5)

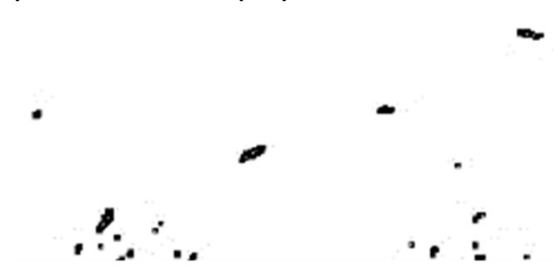

Figure 6. (a) Assumed image of harbour seals. (b) Three dimensional model of a harbour seal; (c) Harbour seal with $1.6 \mathrm{~m}$ of length, at $12 \mathrm{~m}$ of range; and (f) group of four harbour seals with 1.7-2 m of length, at 10-12 $\mathrm{m}$ of range. The shape and silhouette ( $\mathbf{d}$ and $\mathbf{g}$ ) processed using Li and Otsu thresholds and (e and $\mathbf{h})$ using edge and outline filters. 
(a) Grey seal

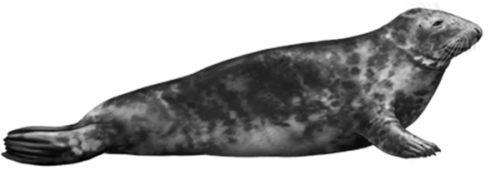

(c) Obs. grey seal (L-3)

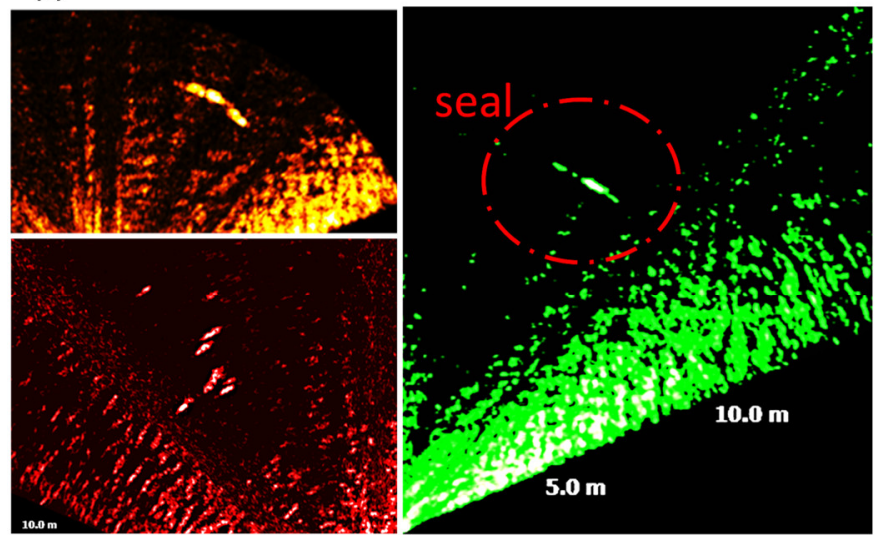

(f) Obs. grey seal (L-3)

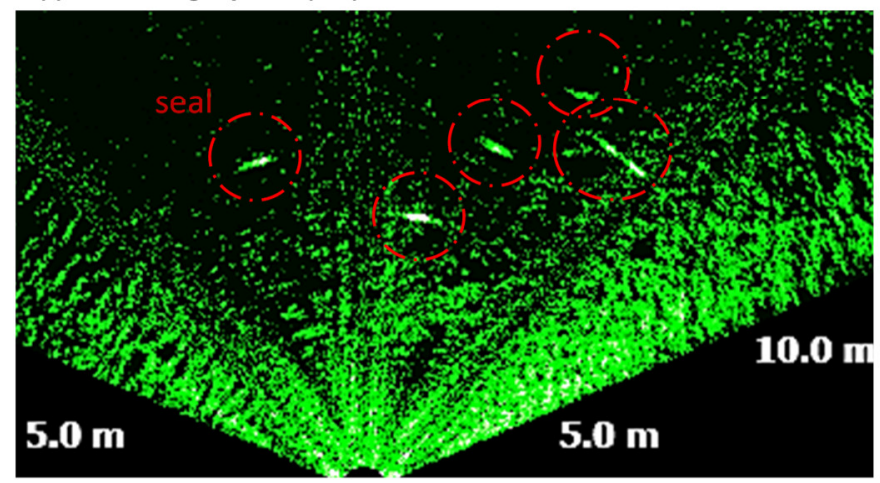

(b) 3D model: grey seal

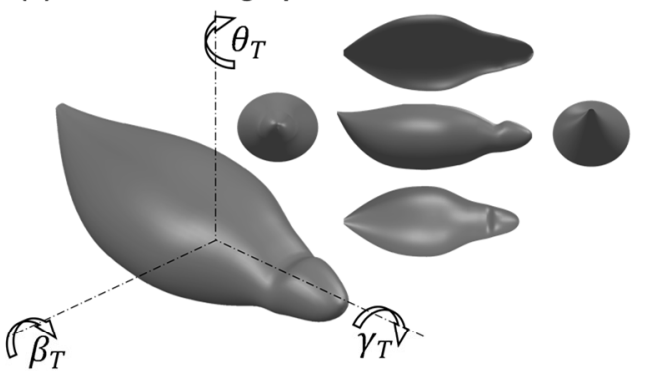

(d) Otsu threshold (L-4)

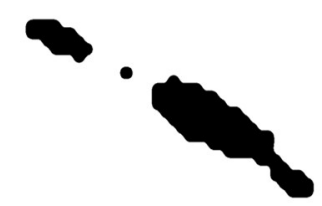

(e) Edge filter (L-5)

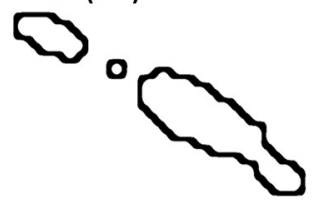

(g) Otsu threshold (L-4)

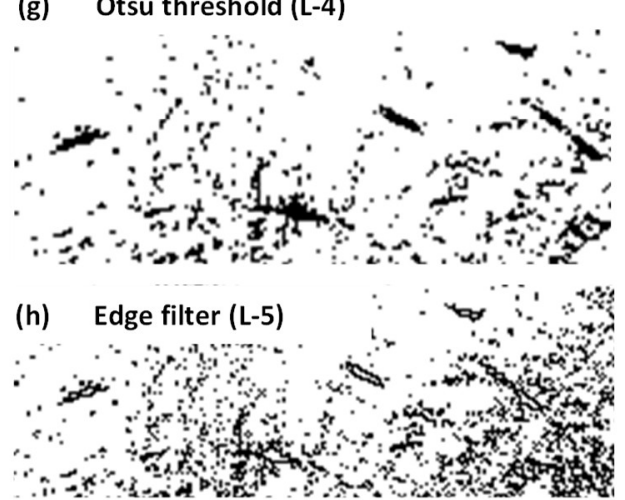

Figure 7. (a) Image of grey seals. (b)Three dimensional model of a grey seal. (c) Acoustic images of grey seals at level 3 , (c) measuring $3 \mathrm{~m}$ of length, located at $6 \mathrm{~m}$ of range; and (f) measuring $2.2 \mathrm{~m}$, located at $6 \mathrm{~m}$ of range. The shape and silhouette of grey seals processed using ( $\mathbf{d}$ and $\mathbf{g}$ ) binary thresholds, (e and $\mathbf{h}$ ) outline filters.

\subsection{Orcas}

The MBS detected large marine mammals $(n=4)$ with the shape and size that matched an orca. These targets occurred isolated at ranges between $5 \mathrm{~m}$ and $16 \mathrm{~m}$ within the FOV, and measured lengths of approximately $4 \mathrm{~m}$ to $7 \mathrm{~m}$ (Figure $8 \mathrm{c}, \mathrm{f}$ ). The measured height of the dorsal fin was $1.3 \mathrm{~m}$ (Figure $8 \mathrm{c}$ ). With respect to target insonification, each processed acoustic image showed a different silhouette while preserving the characteristic shape of a large Delphinidae. Complex target patterns were also observed (Figure 8f), instead of full solid shapes, there were sequential arcs patterns. This was due to the swimming angles of the target in relation to the sonar FOV. Dolphins and whales are known to swim in different positions, displaying a multitude of yaw, pitch and roll angles as they move through water mostly while foraging and hunting (shown in documented video recordings). Orcas appeared on the acoustic image as elongated-sweep targets with streamlined shapes (Figure 8). Remarkably, 
despite having a large body-size, the acoustic signature of the assumed orcas was not bright as would be expected.

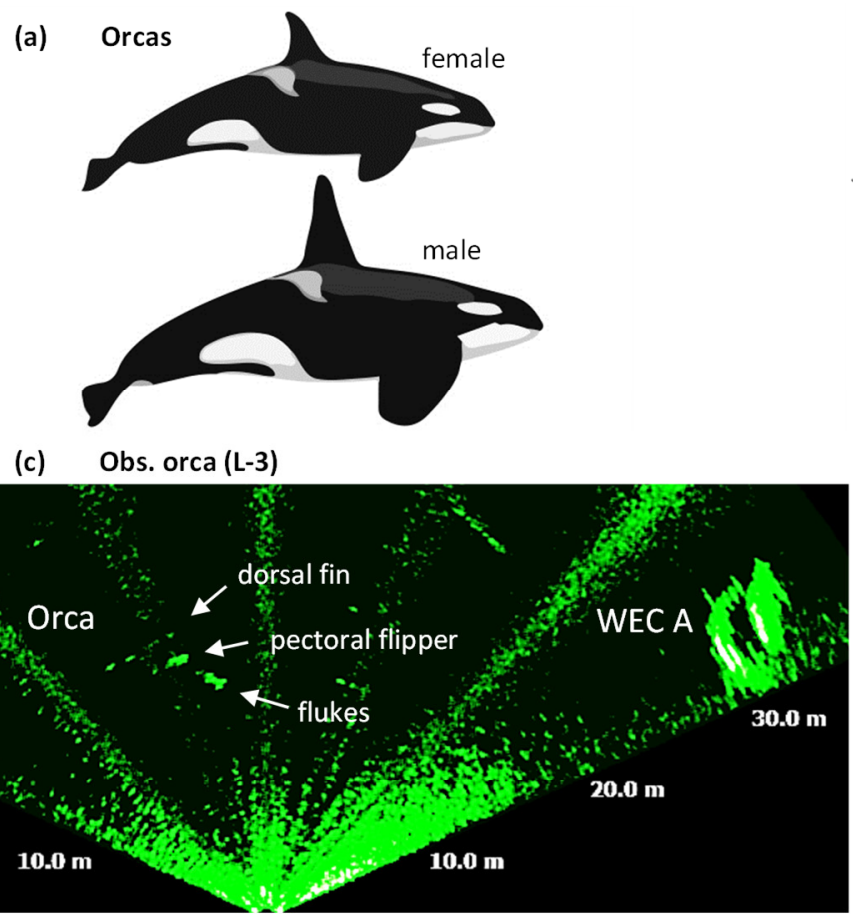

(f) Obs. orca (L-3)

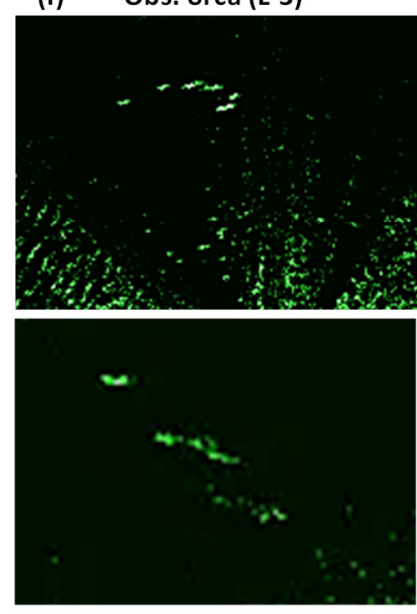

(b) 3D model: orca

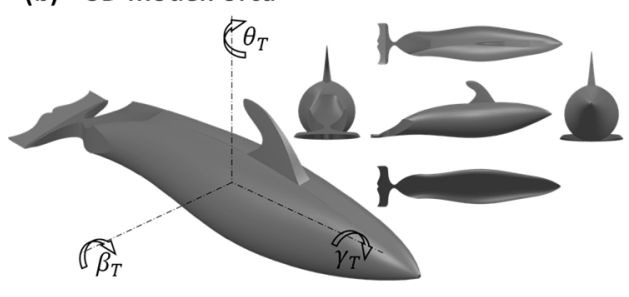

(d) Binary threshold (L-4)

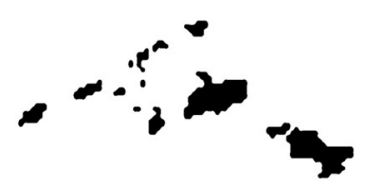

(e) Edge \& skeletonize filters (L-5)

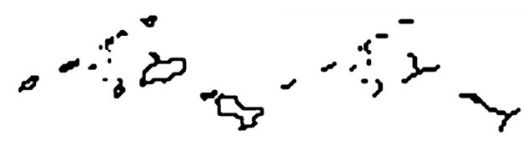

(g) Connected regions (L-4) \& outline (L-5) filters
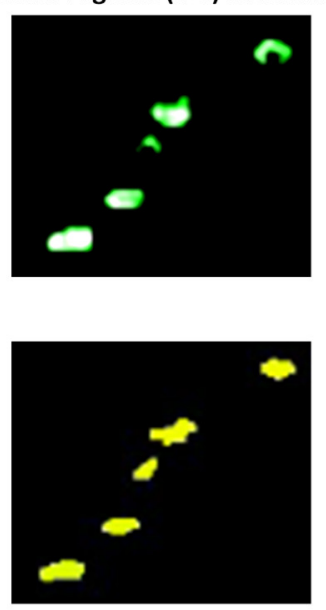

Figure 8. (a) Image of male and female orcas [38]. (b) Three dimensional model of an orca. (c and f) Acoustic images of an orca processed at level 3: (c) An orca with $7 \mathrm{~m}$ of length, located at $16 \mathrm{~m}$ of range, (f) Orca with $4.2 \mathrm{~m}$ of length, at $15 \mathrm{~m}$ of range. The shape and silhouette of orcas processed using (d) binary threshold, (e) outline and skeletonize filters, (g) connected regions, and (h) outline filters.

\subsection{Combined Occurrence of Different Targets}

The simultaneous occurrence of large fish (cod) mid-size fish (most likely herring or mackerel), small-size fish (most likely sprat), harbour and grey seals as well as large marine mammals that were probably orcas are shown in Figure 9. The differences in terms of shape and size among different types of targets were noticeable. 


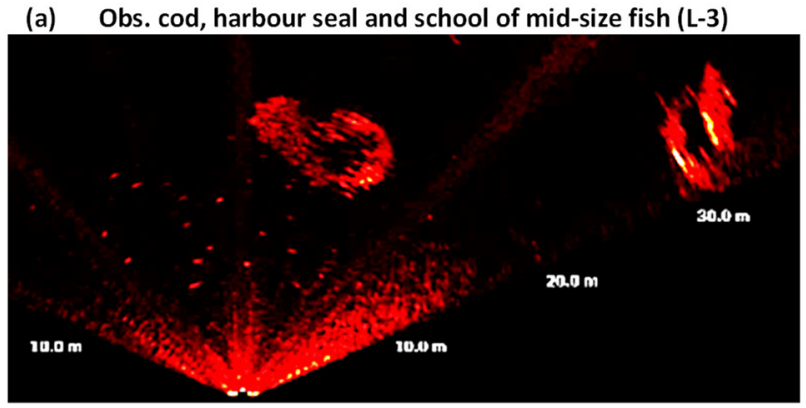

(c) Obs. cod, harbour seal and school of mid-size fish (L-3)

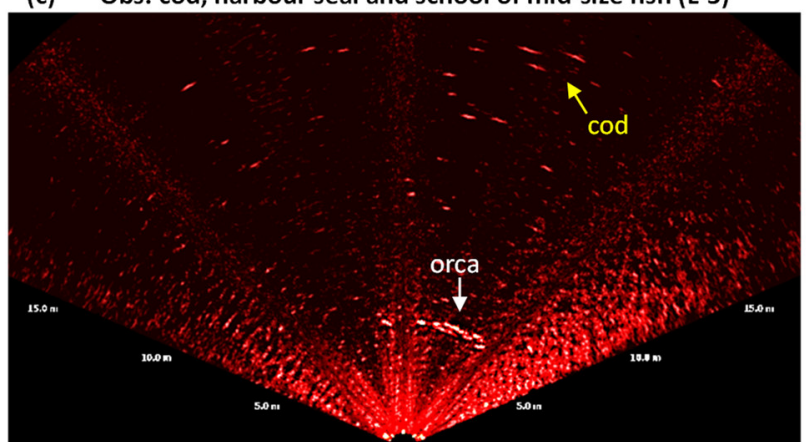

(e) Obs. cod, harbour seal and school of small-size fish (L-3)

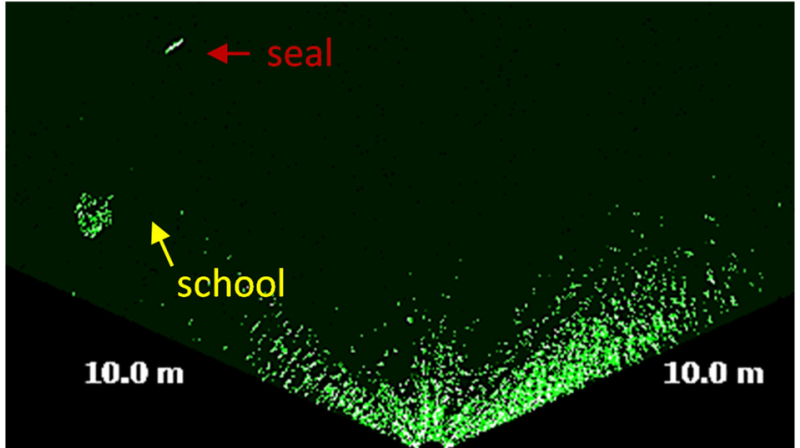

(b) Edge filter (L-4)

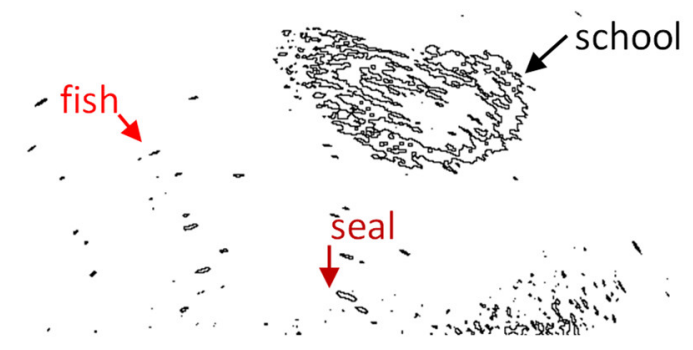

(d) Otsu threshold (L-4)

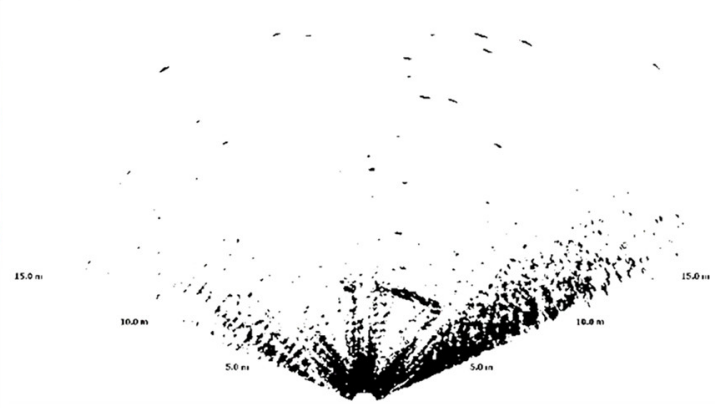

(f) Edge filter (L-5)

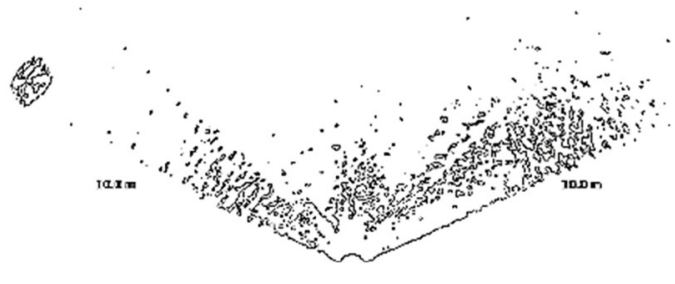

Figure 9. Visual signatures of fish, seals and orcas in simultaneous occurrence. (a) Acoustic image of cod, harbour seals and school of mid-size fish; (b) Shapes of harbour seals, cod and school of mid-size fish processed with edge filter. (c) Cod and an orca, and (d) shapes of cod, and orca processed with binary threshold; (e) School of small-size fish ("sprat"), and grey seals, and the respective shapes (f) processed using edge filter.

The results obtained by processing acoustic images at levels 3-5 ( Figures 4-9) gave unique target features that can be used as signatures. Primarily, these signatures were derived from the image processing algorithms, but the same signatures had been improved using extrapolation, in order to extract the uniform shapes. The two-dimensional shapes of the observed targets are presented in Figure 10, and the respective $x$ and $y$ coordinates can be supplied by the authors upon request. In the near future, these coordinates will be available online through e.g. reference [39]. 
(a) Extracted signatures of cod

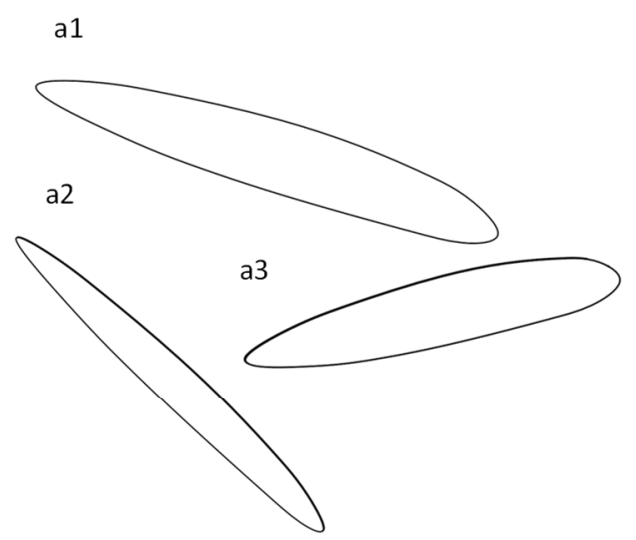

(c) Extracted signatures of grey seal

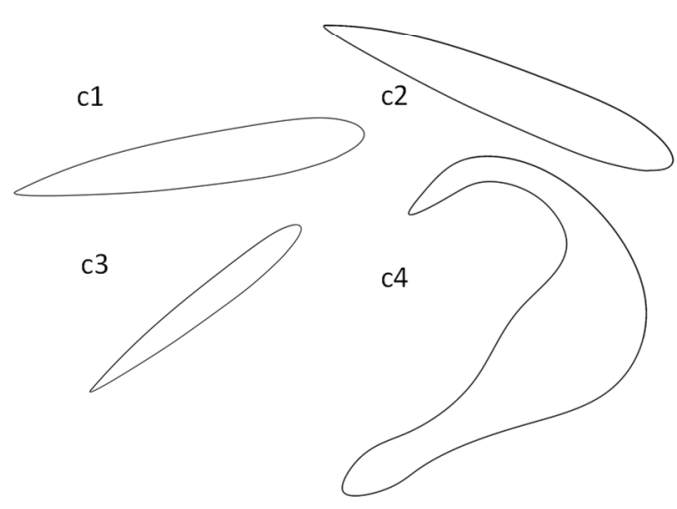

(b) Extracted signatures of harbour seal

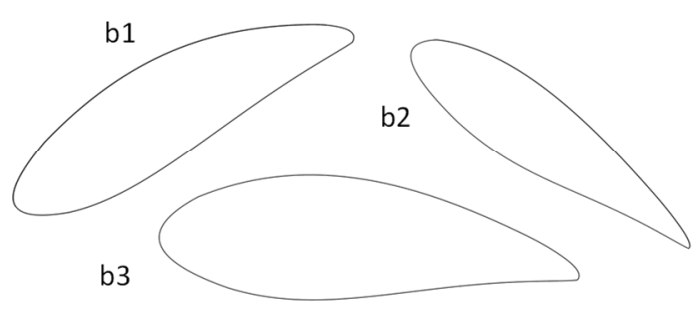

(d) Extracted signatures of orca

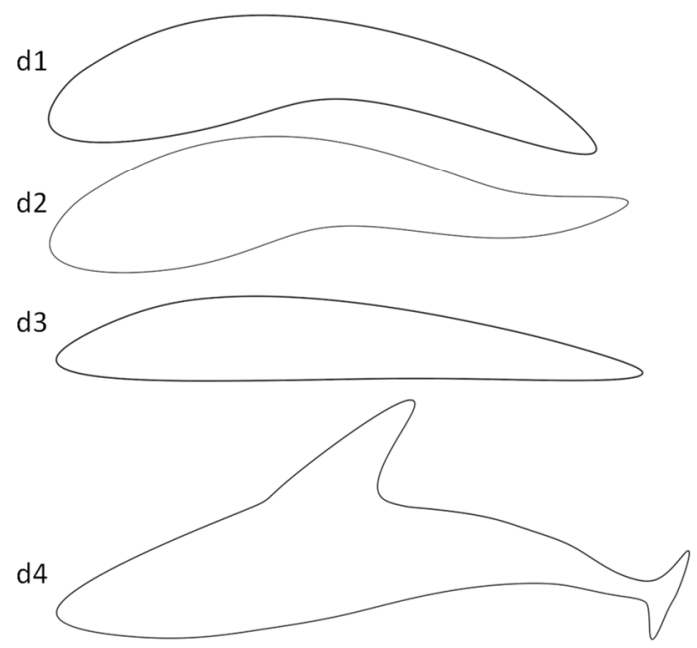

Figure 10. Visual signatures extracted from acoustic imaging of (a) cod, (b) harbour seals, (c) gray seals and (d) orcas. The shapes were extrapolated from several acoustic images and reconstructed using Solidworks.

\section{Conclusions}

This study shows that the multibeam imaging sonar provided interpretive images of the underwater environment surrounding marine renewable energy devices. Filters were applied on the acoustic images in order to extract features such as the shape, size, and swimming behavior of fish and marine mammals. The dataset contained 311,740 images, of which ca. 90\% (ca. 280,566) of them contained targets. First, all the images were processed at level 3, where targets were identified and classified. Then the images were re-processed at the same level 3 in order to reassure the results. After that, 200 images were selected and processed at levels 4 and 5 in order to extract shapes. Then, all the 280,566 images were re-processed at level 3 in order to refine the results. Afterward, images at levels 4 and 5 were re-processed, and finally, the 200 images were then processed at level 6 in order to extrapolate the most commonly occurring shapes, and finally the signatures were extracted.

It was also possible to identify the unique relationship between shape and size that can be assigned as signatures of each respective species group. Ellipsoidal-bulkier, slow-moving targets with lengths of $(20 \mathrm{~cm}$ to $40 \mathrm{~cm})$ were classified as cod (Gadus morhua), fast-moving, ellipsoidal measuring $(1 \mathrm{~m}$ to $2 \mathrm{~m}$ ) were classified as harbour seals (Phocoena phocoena), fast-moving, ellipsoidal - bulkier with length of ( $2 \mathrm{~m}$ to $4 \mathrm{~m}$ ) were classified as grey seals (Halichoerus grypus), and ellipsoidal streamlined-bulkier 
targets with length $(>4 \mathrm{~m}$ ) were classified as orca (Orcinus orca). Small-size targets $(<20 \mathrm{~cm})$ and mid-size targets $(20 \mathrm{~cm}$ to $40 \mathrm{~cm}$ ) were schooling fish with the species being indeterminate. Given the study location they could be sprat (Sprattus sprattus), herring (Clupea harengus), mackerel (Scomber scombrus) but other species of small-size fish also occur in the area [28], [30]. Results of temporal and spatial occurrence of targets presently described were further discussed in a complementary manuscript under construction [40].

There were uncertainties in the estimated values of AVM that could be associated to the species, shape, age, gender and position of the animal in relation to the sonar FOV. Cod and harbour seals were the targets showing the best AVM as compared to grey seals and orcas. This may contradict the presumption that a larger target volume results in better visibility. However, the shape, skin and muscle composition of these animals may affect their acoustic reflectivity. Since no animal was captured, and the actual size measured, there was a need to have a standard measure of length and this was retrieved from the literature. On average, female grey seal measure $2 \mathrm{~m}$, and males measure $3 \mathrm{~m}$ [41-43]. The typical sizes for harbour seals are $1.7 \mathrm{~m}$ for females and $1 \mathrm{~m}$ for males [44,45]. In this region, orcas measure on average $6 \mathrm{~m}$ for females and $7 \mathrm{~m}$ for males. For fish, the typical cod size was $0.9 \mathrm{~m}$, which was the median value between $0.6 \mathrm{~m}$ and $1.2 \mathrm{~m}$ of the documented length of adult Atlantic cod, but the difference in size between sexes of cod is negligible $[28,36,46,47]$. Estimated values of AVM of female harbour seals were much closer to expected values than the estimated AVM of male harbour seals. This may suggest that the observed harbour seals were dominated by females. Similarly, the results also indicated that the observed grey seals were dominated by females. Overall, the results show that there is a negligible relation between the target range and AVM values.

Several other factors affected the visibility of targets on the acoustic images. These factors were pitch-roll-yaw angles in relation to the sonar's FOV, the altitude from the seabed and range of each target and the size of the target itself. The larger the target the more it was affected by its position in relation to the sonar FOV. In terms of dimensions, for example the measured length of cod might be the distance between the mouth and the peduncle (beginning of the tail fin), and not of the entire fish as would be assumable. The area between the mouth and beginning of the tail has larger volume and mass that could have provided greater insonification values, i.e., it reflected more acoustic energy. Another factor related to the measured length can be the yaw angle of the target that might have given an apparent measurement in relation to the sonar FOV. Targets located closer to the seabed were difficult to classify, especially those detected at closer ranges, regardless of their sizes. This is due to the acoustic backscattering of both targets and seabed which are within the same intensity values. Targets located within the water column and not closer to the seabed were easier to classify. Targets located at ranges beyond $40 \mathrm{~m}$ to $50 \mathrm{~m}$ were difficult to detect and classify, with the exception of large schools of fish.

The present work made extensive use of image processing algorithms embedded in Proviwer4 and FIJI in order to analyze the acoustic images. This process was not automatic, therefore requiring a substantial amount of time for data analysis and target classification. The first post-processing phase that leads to an image at level 3 (attributed raw data with target identification), was the step that required special attention. Here, the data analyst needs to filter out noise in order to detect and identify targets. Before the classification process begins, the analyst should have an idea of how the targets of interest may look on an acoustic image. Redundancy on data analysis is particularly important when classifying targets through acoustic images. In most of the times, a level three image can be sufficient to correctly classify targets. However, if the aim is to do detailed metrics of the detected targets, there is a need to process the acoustic images to levels four, five and higher. The unique features or signatures resultant from well resolved targets can be used to instruct computer algorithms to automatically classify targets. The automation of target detection and classification using acoustic images might ultimately revolutionize the actual method of analyzing marine monitoring data.

In summary, the present work in conjunction with other ongoing studies such as reference [40,48,49], concludes that multibeam imaging sonar systems can effectively be used to monitor the underwater 
environment surrounding marine renewable energy devices. Harbour seals, grey seals, orcas, cod, medium to small size fish as well as school of fish could be detected, identified and classified. For example, cod occurred as bright ellipsoidal targets shoaling in groups with fairly similar sizes, moving slowly within the FOV. Harbour seals also appeared as bright torpedo-like targets that move relatively fast across the FOV. Grey seals appeared as bulkier-ellipsoidal targets that constantly rotated their bodies. Orca or larger marine mammals showed a relatively low visibility on the acoustic images comparing to their body sizes. They appeared as large streamlined targets and showed typical body features such as the dorsal fin. However, the low insonification of such large targets may be related to factors such as the skin composition, blubbers thickness, and swimming patterns. School of mid-size fish were easy to classify as they appeared as large, bright and dynamic targets. Schools of small-size fish appeared as slow moving bodies of fish that unaltered their shapes while crossing the FOV. Thus, it may be concluded that certain targets provide better visibility in the acoustic images than others. Smaller and less flexible targets tended to appear brighter than the larger and more flexible targets.

The relationship between target range, size and visibility was not strictly investigated. However, it can be concluded that the position of the target in terms of its yaw, pitch, roll and altitude in relation to the FOV are the defining factors of acoustic image visibility. The newly introduced AVM, which is a new technique of target evaluation, according to shape and size in relation to already known information, needs further improvements. Nevertheless this work concludes that the AVM method can deliver satisfactory results.

Image processing algorithms proved to be essential for extracting target features and identifying signatures or distinct silhouettes in acoustic images. This task proved to be challenging and time consuming. However, the distinct visual signatures of each target can be used to create automatic target classification systems capable of promptly identifying and classifying targets of interest. This may facilitate those interested in using sonar data for detecting and classifying fish, marine mammals, and diving seabirds, among other underwater targets. The AVM technique can also facilitate the environmental impact assessments for pre and post consenting studies in offshore energy farms, etc. The authors wish to encourage further development of imaging sonar technologies and the appropriate data processing techniques.

Author Contributions: F.F. contributed with conception of the work, data collection, analysis and interpretation, drafting and revising manuscript, final approval of the version to be published; J.S. contributed with critical revision of the article, final approval of the version to be published.

Funding: This project has received funding from the European Union's Seventh Framework Programme for research, technological and demonstration under grant agreement no 607656. The authors also wish to thank Carl Trygger's \& J Gust Richert's foundations for funding the acquisition of part of the hardware used in this study.

Conflicts of Interest: The authors declare no conflict of interest.

\section{References}

1. Wilson, B.; Batty, R.S.; Daunt, F.; Carter, C. Collision risks between marine renewable energy devices and mammals, fish and diving birds. In Report to the Scottish Executive. Scottish Association for Marine Science; Scottish Association for Marine Science: Oban, Scotland, 2007; pp. 1-110.

2. Boehlert, G.W.; Gill, A.B. Environmental and ecological effects of ocean renewable energy development: A current synthesis. Oceanography 2010, 23, 68-81. [CrossRef]

3. Ward, E.H.R.D.; Sawyer, T.C. Environmental Assessment, Management and Monitoring of Carnegie Wave Energy's Perth Wave Energy Project. In Proceedings of the 11th European Wave and Tidal Energy Conference, Nante, France, 6-11 September 2015.

4. Francisco, F.; Sundberg, J. Sonar for environmental monitoring. Initial setup of an active acoustic platform. In Proceedings of the International Offshore and Polar Engineering Conference, Maui, HI, USA, 21-26 June 2015.

5. Francisco, F.; Sundberg, J.; Leijon, M. Sonar for Environmental Monitoring: Understanding the Functionality of Active Acoustics as a Method for Monitoring Marine Renewable Energy Devices. In Proceedings of the 11th European Wave and Tidal Energy Conference, Nantes, France, 6-11 September 2015. 
6. Bender, A.; Francisco, F.G.A.; Sundberg, J. A Review of Methods and Models for Environmental Monitoring of Marine Renewable Energy. In Proceedings of the 12th European Wave and Tidal Energy Conference, Cork, Ireland, 27th August-1 September 2017.

7. Geoffroy, M.; Knudsen, F.R.; Fortier, L. Target strengths and echotraces of whales and seals in the Canadian Beaufort Sea. ICES J. Mar. Sci. 2015, 73, 451-463. [CrossRef]

8. Kerrie, P.; Mark, J.; David, B.; Peter, A. Using dual-frequency identification sonar (DIDSON) to estimate adult steelhead escapement in the San Lorenzo river, California. Calif. Fish Game 2010, 96, 90-95.

9. Francisco, F.; Sundberg, J. Sonar for Environmental Monitoring: Configuration of a Multifunctional Active Acoustics Platform Applied for Marine Renewables. Unpublished work. 2016.

10. Williamson, B.J.; Blondel, P.; Armstrong, E.; Bell, P.S.; Hall, C.; Waggitt, J.J.; Scott, B.E. A Self-Contained Subsea Platform for Acoustic Monitoring of the Environment Around Marine Renewable Energy Devices-Field Deployments at Wave and Tidal Energy Sites in Orkney, Scotland. IEEE J. Ocean. Eng. 2016, 41, 67-81.

11. Sparling, C.; Gillespie, D.; Hastie, G.; Gordon, J.; Macaulay, J.; Malinka, C.; Wu, M.; Mcconnell, B. Scottish Government Demonstration Strategy: Trialling Methods for Tracking the Fine Scale Underwater Movements of Marine Mammals in Areas of Marine Renewable Energy Development. Scott. Mar. Freshw. Sci. 2016, 7, 114.

12. Bevelhimer, M.; Colby, J.; Adonizio, M.A.; Tomichek, C.; Scherelis, C.S. Informing a Tidal Turbine Strike Probability Model through Characterization of Fish Behavioral Response Using Multibeam Sonar Output; Oak Ridge National Laboratory: Oak Ridge, TN, USA, 2016.

13. Marine Energy, EMEC: European Marine Energy Centre. Available online: http://www.emec.org.uk/ marine-energy/ (accessed on 1 October 2018).

14. Available online: http:// fundyforce.ca/environment/enviromental-assesment/ (accessed on 1 October 2018).

15. Langhamer, O. Effects of wave energy converters on the surrounding soft-bottom macrofauna (west coast of Sweden). Mar. Environ. Res. 2010, 69, 374-381. [CrossRef]

16. Langhamer, O.; Haikonen, K.; Sundberg, J. Wave power-Sustainable energy or environmentally costly? A review with special emphasis on linear wave energy converters. Renew. Sustain. Energy Rev. 2010, 14, 1329-1335. [CrossRef]

17. Haikonen, K.; Sundberg, J.; Leijon, M. Characteristics of the operational noise from full scale wave energy converters in the Lysekil project: Estimation of potential environmental impacts. Energies 2013, 6, 2562-2582. [CrossRef]

18. Grear, M.; Motley, M. Tidal turbine collision assessment using the bulk and shear modulus of marine mammals' soft tissue. In Proceedings of the Twelfth European Wave and Tidal Energy Conference, Cork, Ireland, 27th August-1 September 2017.

19. Hammar, L. Power from the Brave New Ocean: Marine Renewable Energy and Ecological Risks. Ph.D. dissertation, Chalmers University of Technology, Gothenburg, Sweden, 2014; p. 67.

20. Hovem, J.M. Underwater acoustics: Propagation, devices and systems. J. Electroceram. 2007, 19, $339-347$. [CrossRef]

21. Mcgehee, D.; Jaffe, J.S. Three-dimensional swimming behavior of individual zooplankters: observations using the acoustical imaging system FishTV. ICES J. Mar. Sci. 1996, 53, 363-369. [CrossRef]

22. Waite, A.D. Sonar for Practising Engineers; John Wiley \& Sons Ltd.: Hoboken, NJ, USA, 2002; ISBN 0471497509.

23. Chu, D. Technology evolution and advances in fisheries acoustics. J. Mar. Sci. Technol. 2011, 19, $245-252$.

24. Parwal, A.; Remouit, F.; Hong, Y.; Francisco, F.; Castelucci, V.; Hai, L.; Ulvgård, L.; Li, W.; Lejerskog, E.; Baudoin, A.; et al. Wave Energy Research at Uppsala University and The Lysekil Research Site, Sweden: A Status Update. In Proceedings of the 11th European Wave and Tidal Energy Conference, Nantes, France, 6-11 September 2015.

25. Teledyne PDS. Available online: http://www.teledyne-pds.com/ (accessed on 1 October 2018).

26. Schindelin, J.; Arganda-Carreras, I.; Frise, E.; Kaynig, V.; Longair, M.; Pietzsch, T.; Preibisch, S.; Rueden, C.; Saalfeld, S.; Schmid, B.; et al. Fiji: An open-source platform for biological-image analysis. Nat. Methods 2012, 9, 676. [CrossRef] [PubMed]

27. Priya, M.S.; Nawaz, G.M.K. Multilevel Image Thresholding using OTSU's Algorithm in Image Segmentation. Int. J. Sci. Eng. Res. 2017, 8, 101-106.

28. Stål, J.; Paulsen, S.; Pihl, L.; Rönnbäck, P.; Söderqvist, T. Coastal Habitat Support to Fish and Fisheries on the Swedish West Coast; Department of Marine Ecology, Göteborg University, Kristineberg Marine Research Station: Fiskebäckskil, Sweden, 2007; pp. 1-17. 
29. Pihl, L.; Rosenberg, R. Production, abundance, and biomass of mobile epibenthic marine fauna in shallow waters, Western Sweden. J. Exp. Mar. Bio. Ecol. 1982, 57, 273-301. [CrossRef]

30. Almesj, L.; Lim, H. Fish Populations in Swedish Waters: How Are They Influenced by Fishing, Eutrophication and Contaminants? The Riksdag Printing Office: Stockholm, Sweden, 2009; p. 80.

31. Chudzinska, M. Diving behaviour of harbour seals (Phoca vitulina) from the Kattegat. Master's thesis, Department of Arctic Environment, National Environmental Research Institute, University of Aarhus, Denmark, Aarhus, 2009; p. 69.

32. Härkönen, T.; Harding, K.C. Spatial structure of harbour seal populations and the implications thereof. Can. J. Zool. 2001, 79, 2115-2127. [CrossRef]

33. Solberg, I. Behavior and Ecology of Overwintering Sprat Sprattus Sprattus 2017. PhD dissertation, Faculty of Mathematics and Natural Sciences, University of Oslo, Oslo, Sweden, 2017.

34. Global Biodiversity Information Facility GBIF-Sweden. 2018. Available online: http://www.gbif.se/portal/ \#/index (accessed on 1 September 2018).

35. HELCOM (Baltic Marine Environment Protection Commission-Helsinki Commission). 2018. Available online: http:/ / maps.helcom.fi/website/mapservice/index.html (accessed on 1 September 2018).

36. Cod (Gadus Morhua). European Commission, 2018. Available online: https://ec.europa.eu/fisheries/ marine_species/wild_species/cod_en (accessed on 20 August 2008).

37. Lesage, V.; Hammill, M.O.; Kovacs, K.M. Functional classification of harbor seal (Phoca vitulina) dives using depth profiles, swimming velocity, and an index of foraging success. Can. J. Zool. 1999, 77, 74-87. [CrossRef]

38. Killer Whales: Physical Characteristics. SeaWorld Parks \& Entertainment, 2018. Available online: https: / seaworld.org/animal-info/animal-infobooks/killer-whale/physical-characteristics/ (accessed on 20 August 2011).

39. Uppsala University Publications. DiVA portal: Francisco, Francisco. Available online: http://uu.diva-portal. org/smash / person.jsf?pid=authority-person:21725 (accessed on 1 December 2018).

40. Francisco, F.; Bender, A.; Sundberg, J. Use of Multibeam Imaging Sonar for Observation of Marine Mammals and Fish on a Marine Renewable Energy Site. Unpublished work. 2018.

41. Hastie, G.D.; Donovan, C.; Götz, T.; Janik, V.M. Behavioral responses by grey seals (Halichoerus grypus) to high frequency sonar. Mar. Pollut. Bull. 2014, 79, 205-210. [CrossRef]

42. Hammond, P.S.; Nicholas, K.S.; Fepak, M.A.; Mammal, S.; Antarctic, B.; Cross, H.; Road, M. Movements, diving and foraging behaviour of grey seals. 1991, 224, 223-232.

43. Jefferson, T.A.; Leatherwood, S.; Webber, M.A. Marine Mammals of the World; United Nations Environment Programme: Washington DC, USA, 1993; ISBN 9251032920.

44. Königson, S. Seal behaviour around fishing gear and its impact on Swedish fisheries. Ph.D. thesis, Department of Marine Ecology, Swedish Board of Fisheries, Göteborg University, Göteborg, Sweden, 2007; p. 20.

45. William, F. Perrin; Würsig, B.; Thewissen, J.G.M. Encyclopedia of Marine Mammals, 3rd ed.; Academic Press: San Diego, CA, USA, 2017; ISBN 987-0-12-373553-9.

46. Atlantic Cod: Gadus Morhua Linnaeus. Global Biodiversity Information Facility, 2018. Available online: https:/ / www.gbif.org/species/113235764 (accessed on 20 August 2008).

47. Combourieu, A.; Lawson, M.; Babarit, A.; Ruehl, K.; Roy, A.; Costello, R.; Weywada, P.L.; Bailey, H. WEC3: Wave Energy Converter Code Comparison Project. In Proceedings of the 11th European Wave and Tidal Energy Conference, Nantes, France, 6-11 September 2015.

48. Francisco, F.; Sundberg, J. Evaluation of Underwater Acoustic and Optical Imaging for Structural Inspections for Marine Renewables. Unpublished work. 2018.

49. Francisco, F.; Carpman, N.; Dolguntseva, I.; Sundberg, J. Use of Multibeam and Dual-Beam Sonar Systems to Observe Cavitating Flow Produced by Ferryboats: In a Marine Renewable Energy Perspective. J. Mar. Sci. Eng. 2017, 5, 1-15. [CrossRef]

(C) 2019 by the authors. Licensee MDPI, Basel, Switzerland. This article is an open access article distributed under the terms and conditions of the Creative Commons Attribution (CC BY) license (http:/ / creativecommons.org/licenses/by/4.0/). 